\title{
LA EDICIÓN CRÍTICA Y LA CRÍTICA A PROPÓSITO DE UNA EDICIÓN DE LA OBRA DE BERNARDO ORTIZ DE MONTELLANO
}

La edición crítica, en mi opinión, tiene un objetivo específico, pero también muchos otros destinos alternos igual de importantes: si bien es cierto que su primera intención es fijar una obra, no resulta menos valiosa su misión de alentar un canon de estudios a su alrededor, toda vez que una buena edición crítica sostiene (o debería sostener) el edificio de una reflexión valorativa seria. Una edición de difusión (sean obras completas, sea sencillamente una edición anotada o una edición de bajo costo) raras veces reviste verdadera utilidad para la discusión especializada y, las más veces, la silencia. Sólo recordemos, a título de ejemplo, que el Primero Sueño sorjuanino editado por don Ermilo Abreu Gómez en Contemporáneos (1928) no empezó a ser estudiado seriamente por la academia sino hasta la magna edición de Alfonso Méndez Plancarte en 1951, que aunque todavía no puede llamarse crítica en toda la extensión del término, resultó suficientemente estimulante como para que a partir de ese momento los estudios serios empezaran a menudear. La edición de Abreu Gómez, pese a ser un trabajo pionero, en poco o nada contribuyó a la discusión académica en torno a este texto.

Hoy en día, la edición de la obra poética de Bernardo Ortiz de Montellano preparada por Lourdes Franco ${ }^{1}$ nos ofrece una buena oportunidad para reflexionar sobre las distintas brechas que la edición crítica y la crítica literaria pueden (y, quizá, deben) acortar para empezar a caminar hermanadas, una detrás de otra, para construir por fin ese legado crítico del que tan necesitado ha estado Bernardo Ortiz de Montellano todos estos años. El trabajo de localización y compulsa de versiones hemerográficas y bibliográficas, la reorganización del material poético y las notas en las que se indica su colocación y su disposición estrófica a lo largo de sus distintas ediciones, las líneas

1 Bernardo Ortiz de Montellano, Obra poética, rec., ed., prel., pról., notas e índices L. Franco Bagnouls, UNAM, México, 2005, 417 pp. 
generales para comprender la evolución del proyecto de Ortiz de Montellano como el mayor rasgo de originalidad de este miembro del "grupo sin grupo", son indudablemente los mejores alicientes para salvar el vacío crítico que nunca logró llenar la edición universitaria de Wilberto Cantón y Octavio G. Barreda ${ }^{2}$ en 1952, todavía próxima a la muerte del poeta. Probablemente, la poca oportunidad de su publicación en esta fecha explique en cierta medida la desatención crítica que la rodeó y me sirva, de paso, para ilustrar la escasa fortuna académica de una edición divulgativa. Impresa muy pronto como para que los estudiosos pudieran contar con una perspectiva de la poesía de Ortiz de Montellano más rica y objetiva (de hecho, es la primera copilación de obras poéticas que se hacía de algún miembro de Contemporáneos), quedaba todavía demasiado cercana al amigo y al funcionario público. ¿No es mucha casualidad que la obra de Montellano sea la primera de Contemporáneos en copilarse y publicarse... y la última en leerse? En los otros casos, las obras se copilaron y publicaron en vida de los poetas o en fechas distantes ya a su muerte, con lo que su legado quedó como una herencia en vida o como un tributo funerario; en ambos casos, la obra reunida sirvió como estandarte de consolidación y ocupación de un lugar en el canon. Así, la obra de Novo, muerto hasta 1974, se publica en el Fondo de Cultura Económica en 1961; la obra de Cuesta se copila en 1964, muerto el poeta temprana y trágicamente en 1942; la de Gorostiza es de 1964 también, pero él sobrevive hasta 1973; cuando aparecen las Obras escogidas de Torres Bodet en 1966, publicadas por las prensas del Fondo de Cultura Económica, todavía faltan ocho años para su partida; la de Owen, muerto en 1952, se reúne hasta 1979 y en 1953 , la de Villaurrutia, muerto en 1950. Es muy probable que en la prematura recopilación de la poesía de Ortiz de Montellano se haya visto más como un acto de amistad que como un aporte serio, en un momento en el que, por otro lado, los estudios universitarios sobre la generación inmediata todavía no estaban bien asentados y las preocupaciones seguían siendo sor Juana (la edición de Méndez Plancarte es justamente de 1952) y Ruiz de Alarcón (la de Millares Carlo inicia en 1957), más otros autores considerados cardinales para la formación del canon nacional.

El panorama actual parece más halagador y, aunque hoy mismo la edición crítica de Ortiz de Montellano no puede considerarse la primera del grupo Contemporáneos (ya contábamos con la de Poesía y poética de Gorostiza preparada por Edelmira Ramírez para Archivos, así como con ediciones críticas de poemas sueltos: la de Muerte sin fin de Arturo Cantú, la de Canto a un dios mineral de

2 B. Ortiz de Montellano, Sueño y poesía, nota prel. W. Cantón, Imprenta Universitaria, México, 1952. 
Alberto Pérez Amador-Adam, la de Esquemas para una oda tropical de Samuel Gordon ${ }^{3}$ ), esto garantiza que no vuelva a caer en la incomprensión, sino en un terreno bien abonado en el que la edición crítica de autores modernos se ve con más benevolencia y menos desconfianza.

Al considerar la edición crítica como un faro alentador en los caminos de una reflexión futura, creo que es obligado sugerir algunos de los caminos que hoy pueden augurarse al recorrer los poemas, las notas de ubicación, el aparato de variantes, el prólogo y todas las herramientas con las que nos arma Lourdes Franco en este trabajo. Aunque la edición no puede considerarse una edición genética en sentido estricto (son escasos los manuscritos compulsados ${ }^{4}$ ), habría que tener en cuenta que la información que ofrece sí se orienta por ese camino: expone, por medio de la compulsa cuidadosa de versiones hemerográficas previas con versiones en libro, el taller del artesano y descubre el espíritu creador del artista. Lo primero que salta a la vista del lector, en este sentido, es la simbiosis entre el estudio introductorio y el cuidadoso trabajo de orfebrería realizado en el texto crítico, ambos orientados hacia la explicación concisa del proceso creador, montado sobre los firmes rieles de una voluntad artística y una poética explícita, quizá la más temprana y sostenida de cualquiera de los miembros de Contemporáneos.

Si, como señala Lourdes Franco en el estudio introductorio, Ortiz de Montellano "intenta dolorosamente, a lo largo de toda su obra, construir su gran metáfora, aquella que totalice y resuelva su propia y personal interrogante" (p. 17), dejando ver "en él una línea de creación que se va definiendo a través de sus tres primeros libros y que parte de una vía central de acceso: la inocencia, que lleva aparejadas a un tiempo la sorpresa y la imaginación" (p. 26), lo que hace de Ortiz de Montellano "el único de su generación que sigue en su juventud un proyecto poético determinado" (id.); en el texto crítico, la compulsa

3 Respectivamente, José Gorostiza, Poesía y poética, ed. crítica, coord. E. Ramírez, ALLCA-XX-Archivos, Madrid, 1988; Arturo CAntú, En la red de cristal, edición y estudio de "Muerte sin fin" de José Gorostiza, Universidad Autónoma Metropolitana, México, 1999; Alberto Pérez Amador-Adam, La sumisión a lo imaginario: nueva edición y comento de "Canto a un Dios mineral" de Jorge Cuesta, Vervuert-Iberoamericana, Frankfurt/ M.-Madrid, 2001; Carlos Pellicer, Poesía. Discurso por la Flores. Esquemas para una oda tropical [CD-Rom], coord. ed. S. Gordon, coord. técnica T. Vázquez, UNAM, México, 1996.

${ }^{4}$ Por otro lado, la edición crítica genética de textos latinoamericanos pocas veces ha recurrido a manuscritos, a diferencia de lo que sucede en la tradición europea, por lo que habría que empezar a considerar una definición más amplia para la edición crítica genética que no se limite al estudio y edición de los pre-textos, como demostré en un artículo en colaboración con LAURETTE GoDINAs ("La edición crítica sin manuscritos: otras posibilidades de la edición crítica genética en Balún-Canán de Rosario Castellanos", Incipit, 25, 2005, en prensa). 
exhaustiva de testimonios hemerográficos y bibliográficos ofrece un recorrido por estos caminos con un guía privilegiado. Una revisión del aparato de variantes involucra inmediatamente al lector generoso (aquel dispuesto a brindar unos minutos de su lectura reflexiva al espacio de las variantes a pie de página) con el taller detrás de la obra. Aquí, este lector podrá advertir cómo la poesía de Montellano gana sutileza y madurez en cada edición. Si en las primeras ediciones en $E l$ Universaly El Fígaro de "Sobre la tierra", uno de los poemas iniciales de Avidez (1921), los versos finales se presentan ceñidos a su única contundencia ("Hay un chiquillo que llora: / ise le ha escapado su globo! / Y por esto... ¿quién no llora?”), en la edición en libro de 1921 se refuerza esta imagen de simple trascendencia que confiere Montellano al mundo infantil con un epígrafe latino, "Ex ore parvulorum veritas". Este latinajo debió parecer obvio y molesto para la edición de 1952, donde se elimina para evitar el contraste entre una verdad de tanta simpleza y concentración con los latines un poco pedantescos, sin duda, necesarios para expresar la relevancia poética que tendría la inocencia en Avidez y su obra futura, pero que en la copilación de Cantón y Barreda resultaba obvia por la presencia simultánea de los otros libros de este proyecto temprano, aunque de largo aliento. Lo que en los albores del poeta en 1921 debía enfatizarse, para 1952 resultaría enojoso y repetitivo con una carrera poética tras de sí donde justamente Ortiz de Montellano confería a la inocencia el papel de principal directriz estética de su obra.

En "Letra para cantar", la presencia de los vestigios creativos en Antena, un año anterior a la versión publicada en El trompo de siete colores de 1925, ayuda a entender el contenido referencial: aquí el sutil y enigmático verso de "Ansiedad para mi sed" se explica por su predecesor "Frescura para mi sed" (p. 104); al mismo tiempo, se omite una estrofa en 1925 que ayuda a reconstruir el entramado referencial (y cuya eliminación apunta nuevamente a este propósito de preferir la sugerencia más que la designación precisa): "La indita que a mí te trajo / bien supo lo que me dio: / ipor eso tanto trabajo / persuadirte me costó", versos más bien rudos frente al delicado y sugerente inicio del poema "Del barro fresco de un lago / más hondo que mi canción, / tienes la color y el vago / olor a jarro con flor". En "Los cinco sentidos", el pulimento de las versiones resulta contundente por sí mismo y muestra lo mucho que había avanzado Ortiz de Montellano entre la primera versión, probablemente de 1923, y la de El trompo de siete colores de 1925, donde de un burdo (y poco discreto) "Los jardines de mi tierra / huelen a noche de amor, / como tus oscuras trenzas / húmedas de agua y jabón”, pasa a una estrofa más enigmática y sugerente, donde el honor de la dama queda mejor salvaguardado: "En el telar de la lluvia / tejieron la enredadera / - ¡Madreselva, blanca y rubia!- / de tu cabellera negra"; en esta última versión, el lector ne- 
cesita estar más atento: si bien se mantienen las "trenzas húmedas”, ahora se trata de ver la imagen del cabello negro pasado por "el telar de la lluvia" y de recordar, frente al explícito y rudo "Los jardines de mi tierra / huelen a noche de amor", que las flores de la madreselva son muy aromáticas (no se olvide que el primer "sentido" del poema es justamente el olfato, aunque ahora ya no se expresa de manera obvia y sólo queda apuntado). Al transformar a la madreselva en un término de comparación de la trenza mojada (el "Madreselva, blanca y rubia" proviene de que las flores son blancas cuando nacen y, a medida que envejecen, se tornan amarillas, un contraste que recuerda el de la cabellera negra trenzada con la lluvia), volvemos a tener todos los elementos de la primera versión, pero en un orden complejo que borra el origen referencial: el tópico del cabello delator que, húmedo todavía por el baño reciente y oliendo a flores y a jabón, recuerda esa "noche de amor" por donde había empezado el poeta. En la última versión, el recuerdo de la noche de amor se intensificará necesariamente, como una forma de equilibrio. Ilustrando el sentido del tacto, escribe Ortiz de Montellano en la primera versión: "Cuanto te toco parece / que el mundo me pertenece / porque en tu cuerpo podría / hacer de la noche día”; para la versión definitiva, se borra el condicional "podría" y se da por un hecho que sobre el cuerpo de la amada se posa la luz del amanecer: "Cuando te toco parece / que el mundo a mí se confía / porque en tu cuerpo amanece, / desnudo pétalo, el día”; y ya no sólo no se trata de un cuerpo: es un cuerpo sensual, toda vez que la imagen del "desnudo pétalo" confiere la idea de desnudez, fragilidad y desfloración que da tanta fuerza erótica al poema, sin perder el dejo de inocencia que sirve de orientación a su poesía. Quizá esta forma de proceder quede más clara con las versiones previas de "Martes de carnaval", subtitulado significativamente "Areito", de las que se podan sistemáticamente las reelaboraciones literarias de los ritmos sudamericanos y que sin duda recordaban mucho la poesía de Nicolás Guillén, como sucede con “(Rumbo rumbo ritmo / tono tono tono / Faralaés de plomo / Faralaés de limo)" o "(un son un son un son)", amputados en Sueño y poesía.

En el caso de Ortiz de Montellano no sólo es relevante el mejoramiento estético de los poemas como unidades independientes; importan mucho también aspectos paratextuales y de organización poemática, como la colocación de los textos, el juego con los títulos, su disposición estrófica, etc. Sólo para ejemplificar, la presencia del poema "Paisaje" como cabeza de la sección "Folklore" en El trompo de siete colores de 1925, así como la revisión de los miembros de esta sección ("Romance de amor fugaz", "Navidad", "Los cinco sentidos", "Lo mejor del año", "Amor y olvido", etc.; véase nota de ubicación en "Paisaje", p. 98), obliga a pensar en nuevos sentidos para cada texto, en función del titulado de la sección ("folklore") y de la mezcla no- 
table de tesituras donde, a contrapelo de lo esperado por un título como "conjunto de creencias tradicionales de un pueblo", por darle una definición, se introduce una vena muy personal que confiere una perspectiva humana al conjunto y obliga a repensar el folclor desde la mirada reflexiva e íntima de uno de sus miembros, en franco contraste con nuestra idea del folclor como algo colectivo; este contraste desaparece en Sueño y poesía ante el cambio de organización poemática, si bien persiste con mayor fineza en el ingenioso juego de palabras de "Paisaje": lo que en 1925 fue "Discurre por tal paisaje / mi corazón mexicano" (p. 97), se transforma en 1923 y en 1952 en "Discurre por tal paisaje / mi corazón -monte, llano-", reforzando con la alusión a su apellido la sinécdoque de "corazón”.

Algunos de los poemas más extensos fueron publicados fragmentariamente, lo que abre otros caminos a la interpretación. Es el caso de "Lección", una reflexión moral al estilo de las Meditaciones y Epístolas morales barrocas; aquí, los versos publicados de forma independiente en El Diario de la Marina en 1927 (vv. 1-19 de la edición actual), funcionan como la columna sobre la que se puede sostener la interpretación, toda vez que las estrofas que siguen (presentes ya desde 1923 y hasta 1952) denuncian su papel de mera glosa: en el caso de los vv. 20-28 se trata de una amplificatio que inicia con "Triste -¿será flaqueza?-", en respuesta a los primeros versos "En realidad / apenas tengo edad / para ser triste" (pp. 92-93); en los versos de cierre (vv. 29-36), el par "tristeza/flaqueza" gana peso poético por su mezcla con la experiencia: "Presiento que algún día / esta tristeza mía / ya no será flaqueza sino sabiduría”. Resulta interesante, sin duda, que lo que en los primeros años se percibe como un sentimiento de desasosiego, esta tristeza, se convierta en la madurez en una actividad racional y en un acervo.

En fin, estas son sólo algunas ideas sueltas que van saliendo al paso de una edición crítica modélica, realizada por alguien que no sólo cuenta con todo el rigor y conocimiento del campo, luego de muchos años de frecuentar la obra de Ortiz de Montellano, tanto en verso como en prosa, tanto artística como privada (si recordamos la edición de su correspondencia), sino que muestra también, a cada paso, la curiosidad del niño que intenta descubrir el mundo y que a cada titubeo alcanza un nuevo triunfo: cada página de esta edición, cada línea del estudio introductorio, son pequeños triunfos que conforman una idea más clara, más precisa, de quien fuera uno más de Contemporáneos y, por sí mismo, uno de nuestro poetas más valiosos; poeta con un proyecto muy temprano y original dentro del contexto mexicano que, por ese solo hecho, merecería ya un lugar privilegiado en los anales nacionales de la literatura, lugar que hasta hoy la crítica pocas veces le ha dado pero que, ante la edición amorosa y erudita que nos ofrece Lourdes Franco, resulta una tarea ineludible por más 
tiempo. Si el objetivo de una edición crítica es fijar el texto literario, el de los críticos debería consistir en desmarcarlo de aquí para darle ese movimiento y esa vivacidad que sólo alcanzan los textos en el momento crucial de la lectura.

Alejandro Higashi Universidad Autónoma Metropolitana-Iztapalapa 